Abstracta Iranica

Revue bibliographique pour le domaine irano-aryen

Volume 37-38-39 | 2018

Comptes rendus des publications de 2014-2016

\title{
Erik Anonby, Ashraf Asadi. Bakhtiari Studies. Phonology, Text, Lexicon
}

\section{Chams Bernard}

\section{(2) OpenEdition}

1 Journals

\section{Édition électronique}

URL : http://journals.openedition.org/abstractairanica/43082

DOI : 10.4000/abstractairanica.43082

ISBN : 1961-960X

ISSN : 1961-960X

Éditeur :

CNRS (UMR 7528 Mondes iraniens et indiens), Éditions de l'IFRI

Référence électronique

Chams Bernard, «Erik Anonby, Ashraf Asadi. Bakhtiari Studies. Phonology, Text, Lexicon », Abstracta Iranica [En ligne], Volume 37-38-39 | 2018, document 1, mis en ligne le 30 décembre 2018, consulté le 27 septembre 2020. URL : http://journals.openedition.org/abstractairanica/43082 ; DOI : https:// doi.org/10.4000/abstractairanica.43082

Ce document a été généré automatiquement le 27 septembre 2020

Tous droits réservés 
Erik Anonby, Ashraf Asadi. Bakhtiari Studies. Phonology, Text, Lexicon

Chams Bernard 


\section{RÉFÉRENCE}

Erik Anonby, Ashraf Asadi. Bakhtiari Studies. Phonology, Text, Lexicon. Uppsala, Acta Universitatis Upsaliensis, 2015, 222p. (Studia Iranica Upsaliensia 24).

1 Ce livre, qui est en réalité le premier tome d'une série (Bakhtiari Studies II: Orthography des mêmes auteurs a été publié il y a peu), doit être lu comme tel : il s'agit d'une introduction à la langue bakhtiari préliminaire à la discussion de l'orthographe bakhtiare qui est le sujet du second tome. Le dialecte choisi pour l'étude est celui parlé par Ashraf Asadi, c'est un des dialectes du groupe « Haft Lang », de la région autour de Masjed Solaymān (p. 20).

2 Les auteurs offrent, après une introduction (pp. 15-20), une riche étude de la phonologie du bakhtiari (pp. 21-90), incluant, chose relativement rare, une description très concrète de l'intonation dans cette langue (pp. 67-69). Cette étude est agrémentée de nombreuses phrases en bakhtiari. La partie suivante (pp. 91-120) contient un texte, glosé et traduit. Les pages 121 à 153 présentent la morphologie verbale, et contiennent de très nombreux paradigmes verbaux (pp. 130-153). La cinquième et dernière partie (pp. 155-218) contient un lexique anglais-bakhtiari-persan (le persan est en transcription latine, tout comme le bakhtiari). Ce lexique est classé par thème : on $y$ trouve, par exemple, des termes liés aux parties de la maison (pp. 180-181), à la chasse (pp. 184-185), aux instruments de musique (p. 188), chaque thème étant lui-même intégré dans un plus grand thème (tels que, entre autres, l'habitation, la chasse \& la pêche, ou les loisirs). Le lexique, comme le texte traduit, et les exemples utilisés par les auteurs, proviennent des recherches et des travaux de terrain d'Ashraf Asadi (cf. p. 20).

3 Cet ouvrage permettra à qui s'y intéresse d'avoir une vue d'ensemble assez approfondie de la langue bakhtiari, à travers l'étude poussée d'un de ses dialectes.

\section{AUTEURS}

CHAMS BERNARD

Paris 